\title{
Exploring the Influence of Gender Empowerment on Water, Sanitation and Hygiene: A Study on Peri-Urban Communities in Abuja, Nigeria
}

\author{
Tamara Otonoku1,2*, Adeboye Awomuti1,2, David Omata1,2 \\ ${ }^{1}$ UNEP-Tongji Institute of Environment for Sustainable Development (IESD), College of Environmental Science and Engineering \\ ${ }^{2}$ State Key Laboratory of Pollution Control and Resource Reuse, College of Environmental Science and Engineering, Tongji \\ University, Shanghai, China \\ Email: *otonokutamara92@gmail.com
}

How to cite this paper: Otonoku, T., Awomuti, A. and Omata, D. (2021) Exploring the Influence of Gender Empowerment on Water, Sanitation and Hygiene: A Study on Peri-Urban Communities in Abuja, Nigeria. Open Access Library Journal, 8: e7402. https://doi.org/10.4236/oalib.1107402

Received: April 9, 2021

Accepted: May 28, 2021

Published: May 31, 2021

Copyright $\odot 2021$ by author(s) and Open Access Library Inc.

This work is licensed under the Creative Commons Attribution International License (CC BY 4.0).

http://creativecommons.org/licenses/by/4.0/

\begin{abstract}
Despite evidence indicating that women are disproportionately affected by the lack of proper and secure sanitation facilities worldwide, there is insufficient information on factors influencing the ability of women, especially in sub-Saharan Africa, to access and utilize sanitation. A mixed methods approach was used to collect data on household characteristics, decision-making capabilities, and socio-cultural behaviours among 314 respondents in Aso C, Gishiri and Kuruduma communities in Abuja, Nigeria. First, we used the Empowerment in Water, Sanitation and Hygiene Index (EWI) tool to calculate the ratio of women and men who were empowered, as well as the level of empowerment. Then, we examined the relationship between empowerment and gender, age, literacy level, income levels, willingness to pay for waste water treatment services (WTPWWT) and types of sanitation facilities in the three communities. The findings from this study indicated that control over household assets contributed the most to disempowerment in women. Empowerment levels for both men and women were strongly influenced by income and WTPWWT. By adopting the EWI model for identifying gender disparities, this paper aims to assist practitioners and researchers in organizing, planning, and reporting gender outcomes associated with Water, Sanitation and Hygiene (WASH) programs.
\end{abstract}

\section{Subject Areas}

Environmental Sciences 


\section{Keywords}

Gender Equality, Women Empowerment, WASH, Nigeria

\section{Introduction}

In order to achieve equitable access to water, sanitation and hygiene (WASH), it is essential to address gender disparity. WASH should embody all values of human rights, including "freedom and non-discrimination" and "participation and inclusion". Sustainable Development Goal 6 (SDG 6) sets standards for achieving universal and equal access to water, sanitation and hygiene by 2030.

Research has shown that insufficient access to WASH has many impacts on women and girls, including reducing their involvement in the labour market and community activities thereby, leading to psychosocial stress and poor educational outcomes. There is rising recognition that addressing the WASH-related gender inequalities faced by many women and girls on a daily basis must go beyond concentrating on the provision of infrastructure and facilities alone and paying attention to empowerment issues. Nevertheless, there is limited exploration of how the definition of empowerment in the WASH sector is described and implemented thus, limited data on how it can be determined [1]. Clearly, there are variations, but women and girls are the most affected and disadvantaged among most social classes, especially within socially marginalized groups. This involves limitations on women and girls that, among other concerns, deem health and safety issues, their integrity and economic disadvantage [2]. Increasing evidence of gender-based violence related to sanitation illustrates a number of risks faced by women and girls who are forced to defecate openly or go to shared sanitation facilities. The fear of sexual harassment that can limit free movement and affect equal opportunities is represented in this data [3].

Reports from Ethiopia [4], India [5] [6], and refugee or internally-displaced persons camps in Guinea, Haiti, Kenya, Liberia, the Philippines, Sierra Leone and Somalia [7] record physical and sexual abuse and attack by non-partners, fear of sexual harassment, assault and stress faced by women and girls while accessing openly shared sanitation facilities or defecating openly. More research is required on the prevalence of gender-based violence associated with sanitation and the relationship between access to water and sanitation, gender-based violence and health [3].

The Empowerment in WASH ties SDG 5: "Achieving gender equality and empowering all women and girls" and SDG 6: "Clean Water and Sanitation for all" by allowing clear gaps in the power of women to be established to ensure that their WASH needs are met. This bridges a crucial data gap in the distribution of equitable access to WASH services in line with SDG target 6.2, which addresses access to equitable sanitation and hygiene and the needs of women and girls. Indicators are, however, still evolving to address the particular needs of 
women and girls [3]. By promoting women empowerment, it is also contributing to SDG 8: Decent work and economic growth, SDG 4: Inclusive and equitable education and SDG 10: Reduced inequalities [8].

Incorporating a gender perspective is critical for the WASH field as it may allow rights for advancement for women who are critically under-represented to recognize additional evidence-based benefits (or even harms) of important and relevant interventions [9]. When women engage in planning WASH, their rights to water supply and sanitation are more likely to be fulfilled through available, safe, and affordable services [10]. Universal coverage of WASH in sub-Saharan Africa will offer women and girls an annual return of 40 billion hours currently spent collecting water for their families, freeing up time to pursue education and economic opportunities [11].

In order to generate better evidence on the relation between improved WASH services and the well-being outcome, a greater understanding of the process of empowering women and girls in the water and sanitation sector is required [12]

[13] This paper focuses on its use in relation to WASH to women's empowerment, to explain how the EWI technique offers details on gender-based inequalities.

This study revolves around two key questions:

1) How do we determine gender inequalities in relation to WASH and women's empowerment?

2) How do social identities interact with gender to influence empowerment?

\section{Materials and Methods}

\subsection{EWI Conceptual Framework}

The EWI is a novel tool modelled by Dickin et al. [14] from the Women Empowerment in Agriculture Index (WEAI) [15]. It describes a multidimensional process of empowerment that centres on an interaction between WASH related agency and opportunity that leads to human wellbeing outcomes, a framework adapted from Kabeer [16] and Alsop and Heinsohn [17].

The EWI comprises twelve indicators that are combined in order to measure empowerment across different levels and dimensions. An index strategy offers a clear way for nuanced information to be illustrated and shared, allowing lower scoring parameters to be tracked and prioritized. Indicators provide information unique to WASH duties and obligations within the family, community and in relation to local service providers, as well as wider social empowerment indicators. The indicators of individual, household and societal levels used in the EWI are listed in (Table 1) in more detail. They rely on current literature on empowerment adapted to the scope of WASH [18].

\subsection{Data Collection and Analysis}

The EWI uses individual-level survey data obtained from a male and female respondent living in the same household. Surveys were conducted identifying 
Table 1. Indicators used in EWI.

\begin{tabular}{|c|c|c|}
\hline Level & Indicator & Description \\
\hline Individual & $\begin{array}{l}\text { Intrinsic attitudes about WASH roles } \\
\text { and responsibilities }\end{array}$ & $\begin{array}{l}\text { States views as to whether the respondent can make their } \\
\text { own personal choices about participating in WASH } \\
\text { activities, if they decide to. }\end{array}$ \\
\hline \multirow[t]{8}{*}{ Household } & $\begin{array}{l}\text { Input into decisions about WASH roles } \\
\text { and responsibilities }\end{array}$ & $\begin{array}{l}\text { Investigates if the individual is involved in decisions } \\
\text { regarding fetching water, managing the use of water } \\
\text { within the household and maintaining household } \\
\text { sanitation facilities. }\end{array}$ \\
\hline & Input into decisions about WASH expenditures & $\begin{array}{l}\text { Assesses feedback decisions regarding WASH spending, } \\
\text { divided into household expenditure on water (fees, } \\
\text { containers, etc.), and household expenditure on } \\
\text { sanitation (building and maintaining facilities, } \\
\text { desludging, etc.). }\end{array}$ \\
\hline & $\begin{array}{l}\text { Input into decisions about involvement in community } \\
\text { WASH activities }\end{array}$ & $\begin{array}{l}\text { Evaluates input into household decisions on who } \\
\text { should be involved in community planning of } \\
\text { water facilities or resolving issues. }\end{array}$ \\
\hline & $\begin{array}{l}\text { Ownership and control over household } \\
\text { assets }\end{array}$ & $\begin{array}{l}\text { Ascertains single or joint ownership of household } \\
\text { properties, such as water or toilet facilities, furniture, } \\
\text { electronics, houses or lands, modes of transport (e.g., } \\
\text { car, bicycle, tricycle). }\end{array}$ \\
\hline & Work balance & $\begin{array}{l}\text { Evaluates the time used for jobs, including paid work } \\
\text { (agrarian activities, salary or other wealth-generating } \\
\text { work) and unpaid work (fetching water, parenting, } \\
\text { cooking, etc.) compared to recreation or rest. }\end{array}$ \\
\hline & Time for water collection practice information & $\begin{array}{l}\text { Assesses the time used exclusively for fetching water. } \\
\text { The SDG target } 6.1 \text { indicator uses } 30 \text { minutes to collect } \\
\text { water as a benchmark for a round-trip. }\end{array}$ \\
\hline & Access to and sharing of WASH & $\begin{array}{l}\text { Measures access to sharing of information within the } \\
\text { household about WASH practices (e.g., storing water } \\
\text { safely). }\end{array}$ \\
\hline & $\begin{array}{l}\text { Access to and sharing of information on WASH } \\
\text { rights and responsibilities }\end{array}$ & $\begin{array}{l}\text { Evaluates access to and sharing information on WASH } \\
\text { rights and duties of service providers within the } \\
\text { household (e.g., right to water and sanitation, standards } \\
\text { for service regulators providing water and sanitation). }\end{array}$ \\
\hline Societal (Community) & Group membership & $\begin{array}{l}\text { Reports on whether the individual participates actively } \\
\text { in group organizations, like water-user unions or other } \\
\text { socioeconomic groups (e.g., agricultural producers' } \\
\text { groups, savings associations). }\end{array}$ \\
\hline \multirow[t]{2}{*}{$\begin{array}{l}\text { Local WASH } \\
\text { institutions and } \\
\text { authorities }\end{array}$} & Leadership in WASH implementation & $\begin{array}{l}\text { Addresses if the respondent feels comfortable speaking } \\
\text { publicly in a community meeting to assist in deciding on } \\
\text { water projects (such construction of water supplies) or } \\
\text { implementing sanitation programs. }\end{array}$ \\
\hline & Leadership in WASH accountability & $\begin{array}{l}\text { Addresses whether the respondent is comfortable } \\
\text { enough to speak publicly to express concerns } \\
\text { regarding water services in the community (such as } \\
\text { breakdowns, insufficient services, low quality) or to } \\
\text { report to community heads. }\end{array}$ \\
\hline
\end{tabular}

Source: Dickin, S., Bisung, E., Nansi., et al. (2020). 
participants who identified as key members within the household responsible for making socio-economic decisions. This was conducted as long as there was one adult male and one adult female, a husband and wife, or other members. On the basis of their population size of less than 5000 inhabitants, three communities in the Federal Capital Territory (FCT), Abuja, namely Aso C, Kuruduma and Gishiri, were selected. Using questionnaires, a team of enumerators were trained to conduct the survey. We performed field-mapping of the communities prior to the survey and in order to obtain clarity, survey questions were revised with the enumerators.

Interviewers clarified the informed consent process before each aspect of data collection, including the study's intent and scope, as well as the fact that engagement was voluntary and that respondents could withdraw their consent at any point during the process. After that, participants either gave their verbal consent to begin the interview or refused to do so. There were no personal identifiers registered.

In each community, the survey team targeted about 52 households, working in pairs. We used the EPI random walk method to randomly select the direction and first house to survey [19]. In order to get the most truthful answers, the surveyors were told to perform interviews alone where possible. Using the SPSS software version 25 , data was analysed. With the methodology below, the EWI was determined.

\subsection{Calculating EWI}

A respondent "acquires" a specific indicator for each of the 12 indicators if she or he reaches a certain limit (e.g., a respondent has a certain amount of input into a decision). The degree of accomplishment of respondents is used for measuring the EWI. In each of the indicators, empowered individuals are defined as those who score at least $75 \%$. This applies the threshold used in the WEAI project level [20]. In this way, a respondent can achieve a specific indicator such as "access to and sharing of WASH information" but still be deemed disempowered if they are not scored high on the other indicators. The criterion is subjective and is designed to make sure that not everyone is empowered in order to make comparisons across various scenarios or over a period of time [21].

\subsubsection{Empowerment Ratio (ER)}

The first variable of the EWI is the Empowerment Ratio ER. It is estimated as the number of respondents achieving $75 \%$ indicators, $N_{\text {empowered, }}$ divided by the total population survey, $N$. Therefore, the disempowerment ratio, DR, is 1-ER.

$$
\mathrm{ER}=\frac{N_{\text {empowered }}}{N}
$$

\subsubsection{Disempowerment Ratio (DR)}

$$
\mathrm{DR}=1-\mathrm{ER}
$$




\subsubsection{Level of Achievement (LA)}

LA reports the average level of achievement of indicators noted $p$ that were achieved for the disempowered respondents.

$$
\mathrm{LA}=\frac{\sum p_{\text {disempowered }}}{N_{\text {disempowered }}}
$$

\subsubsection{Empowerment in WASH Index (EWI)}

Using these components, EWI is obtained through a simple calculation;

$$
\mathrm{EWI}=\mathrm{ER}+(\mathrm{DR} \times \mathrm{LA})
$$

\section{Results and Discussion}

Table 2 contains descriptive attributes of the respondents. The results of the EWI in Aso C, Kuruduma and Gishiri showed that male respondents were more empowered than female respondents in $\mathrm{WASH}$, as $6 \%$ and $3 \%$ respectively represents the percentage of empowered respondents (those who met at least $75 \%$ in each of the indicators), suggesting that most female respondents in WASH were disadvantaged.

The level of achievement (LA) was higher for males (41\%) among the disempowered respondents compared to female respondents (32\%). This suggests that to become empowered, women still have to make more efforts. The corresponding EWI score was 0.45 for males and 0.34 for females which is scored between 0 and 1.

Disaggregating these results by indicators reveal where the greatest disparities in empowerment exist. Figure 1 reflects the proportion of female and male disempowered respondents who do not achieve each indicator, showing which indicators contribute more to disempowerment. Control over household assets, input into decisions about involvement in community WASH activities, leadership in WASH accountability, input into decisions on WASH expenditures, personal decisions on WASH roles and leadership in WASH implementation were the top indicators leading to women's disempowerment.

The only indicator contributing to disempowerment for male respondents was work balance.

\section{Association with Socio-Economic Factors}

Although the EWI focuses on empowerment within activities and responsibilities related to water, sanitation and hygiene, empowerment is a cross-cutting

Table 2. EWI scores for male and female respondents.

\begin{tabular}{ccc}
\hline & Men & Women \\
\hline Disempowerment ratio & $93.9 \%$ & $96.8 \%$ \\
Empowerment ratio & $6.1 \%$ & $3.2 \%$ \\
Level of achievement of empowered respondents & $41 \%$ & $32 \%$ \\
Empowerment in WASH Index & 0.45 & 0.34 \\
\hline
\end{tabular}




\section{Disempowerment Ratio}

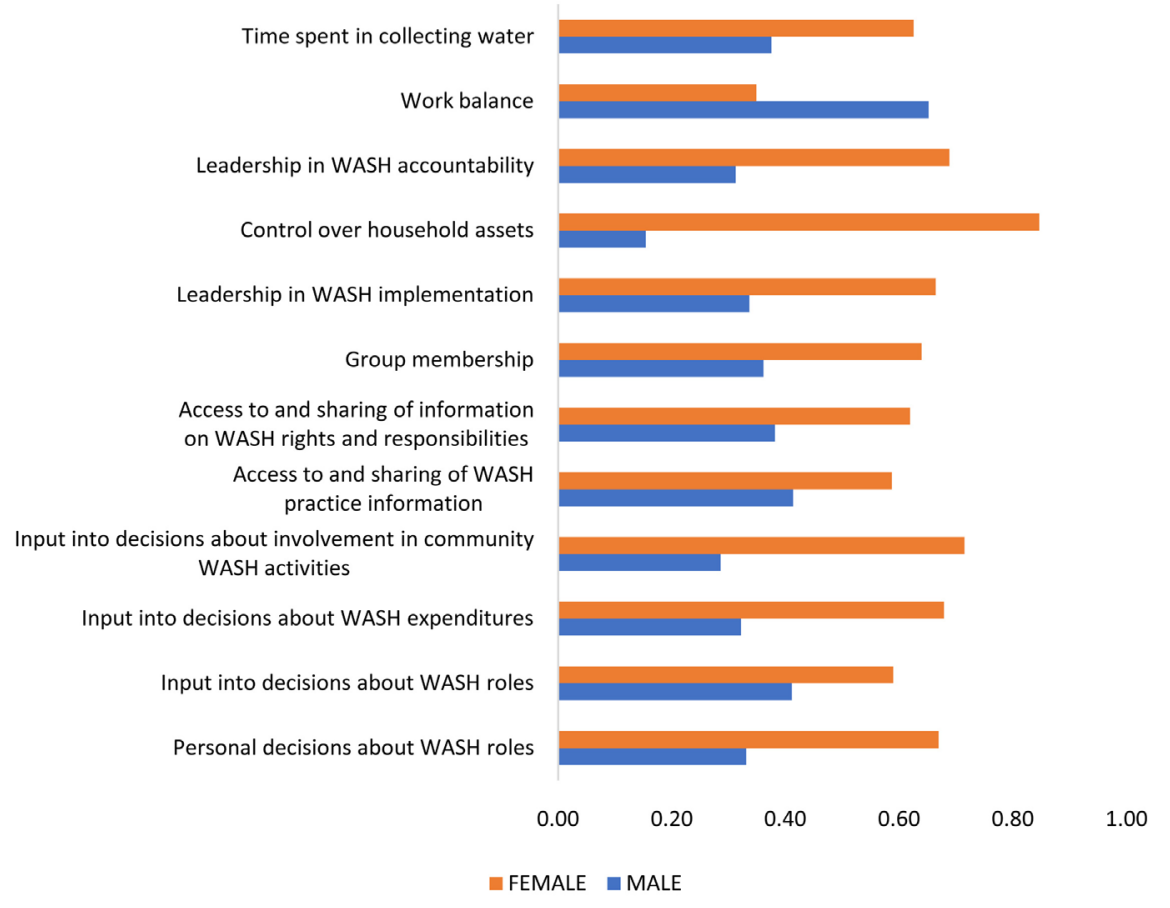

Figure 1. Fraction of disempowered participants who do not meet each indicator.

term. The relationships between the provision of clean water and sanitation services and the empowerment of women have often been promoted but the EWI allows more in-depth analysis of these associations [14].

Based on the number of empowered individuals, the Pearson chi-squared test was conducted with age, academic ability, income levels, type of sanitation facilities, and willingness to pay for waste water treatment services (WTPWWT) to investigate their interactions with empowerment.

The results of the analysis in Table 3 highlighted relationships between socioeconomic proxies and empowered respondents, although further research is required to verify them at scale. Women who had attained a tertiary school level of education were four times more likely to be empowered compared to those who had no form of education. In the same manner, men who used improved sanitation facilities in their household (flush to septic tank) in their household had more than two times the odds of being empowered compared to those with unimproved sanitation (open defecation).

Based on the socio-economic characteristics analysed, income levels and WTPWWT had significant relationships with empowerment (Pearson chi-squared values 0.038 and 0.008 respectively).

In Figure 2, respondents earning between 20,000 - 49,000 naira (41.8 - 102.5 US dollars) were the most empowered as they constituted $72 \%$ of the empowered respondents. As shown in Figure 3, 93\% of the empowered respondents were willing to pay a monthly fee of 500 naira and above ( 1 U.S dollar and above) for wastewater treatment services. 
Table 3. Association with empowerment based on socio-economic characteristics.

\begin{tabular}{|c|c|c|}
\hline Characteristics & $\begin{array}{c}\text { Empowered } \\
\text { Men }\end{array}$ & $\begin{array}{c}\text { Empowered } \\
\text { Women }\end{array}$ \\
\hline \multicolumn{3}{|l|}{ Age (Years) } \\
\hline $15-25$ & - & $7.7 \%$ \\
\hline $26-39$ & $15.8 \%$ & $7.8 \%$ \\
\hline $40-49$ & $10.8 \%$ & $4.4 \%$ \\
\hline $50-59$ & - & - \\
\hline 60 and above & - & - \\
\hline Pearson-chi ${ }^{2}$ (p-value for both men and women) & 0.268 & \\
\hline \multicolumn{3}{|l|}{ Education levels } \\
\hline Uneducated & $8.3 \%$ & - \\
\hline Primary & $14.3 \%$ & $6.1 \%$ \\
\hline Secondary & $11.4 \%$ & $8.5 \%$ \\
\hline Tertiary/University & $9.8 \%$ & $4.8 \%$ \\
\hline Advanced & - & - \\
\hline Pearson-chi ${ }^{2}$ ( $\mathrm{p}$-value for both men and women) & 0.942 & \\
\hline \multicolumn{3}{|l|}{ Income levels (in Naira) } \\
\hline Less than 20,000 & $4.9 \%$ & $1.61 \%$ \\
\hline $20,000-49,000$ & $15.5 \%$ & $12.3 \%$ \\
\hline $50,000-99,000$ & $10.8 \%$ & $6.7 \%$ \\
\hline $100,000-200,000$ & - & - \\
\hline 200,000 and above & - & - \\
\hline Pearson-chi ${ }^{2}$ (P-Value for both men and women) & $0.038^{*}$ & \\
\hline \multicolumn{3}{|l|}{ Type of toilet/sanitation facility } \\
\hline Flush to sewer system & - & - \\
\hline Flush to septic tank & $15.6 \%$ & $7.3 \%$ \\
\hline Pit latrine & $2.6 \%$ & $7.1 \%$ \\
\hline Open drain & - & - \\
\hline Bush/open defecation & $6.7 \%$ & $7.7 \%$ \\
\hline Pearson-chi ${ }^{2}$ (P-value for both men and women) & 0.298 & \\
\hline \multicolumn{3}{|l|}{ (WTPWWT) (in Naira) } \\
\hline Not Willing & $5.4 \%$ & - \\
\hline 200 & - & - \\
\hline 500 & $2.1 \%$ & $16.1 \%$ \\
\hline 1000 & $23.5 \%$ & $2.1 \%$ \\
\hline 2000 & $10.3 \%$ & $4.5 \%$ \\
\hline 5000 & $33.3 \%$ & $37.5 \%$ \\
\hline Pearson-chi ${ }^{2}$ (P-value for both men and women) & $0.008^{*}$ & \\
\hline
\end{tabular}

${ }^{*}$ Statistical significance, $\mathrm{p}<0.05$.

There were no significant associations in empowerment for either women or men when comparing age, education levels and type of sanitation facilities.

We used the EWI framework of Dickin et al. [14] to explore studies and links between women and WASH in three peri-urban communities in Abuja. Our findings revealed a difference between men and women respondents. Control over household assets contributed the least to women empowerment in WASH. A potential reason is that women have a lower socio-economic status due to lower levels of income and employment. Cultural values may also be a likely limitation, as socio-cultural expectations vary. Equity is one major reason to reflect on the gender asset and income disparities. Fair access to and power over 


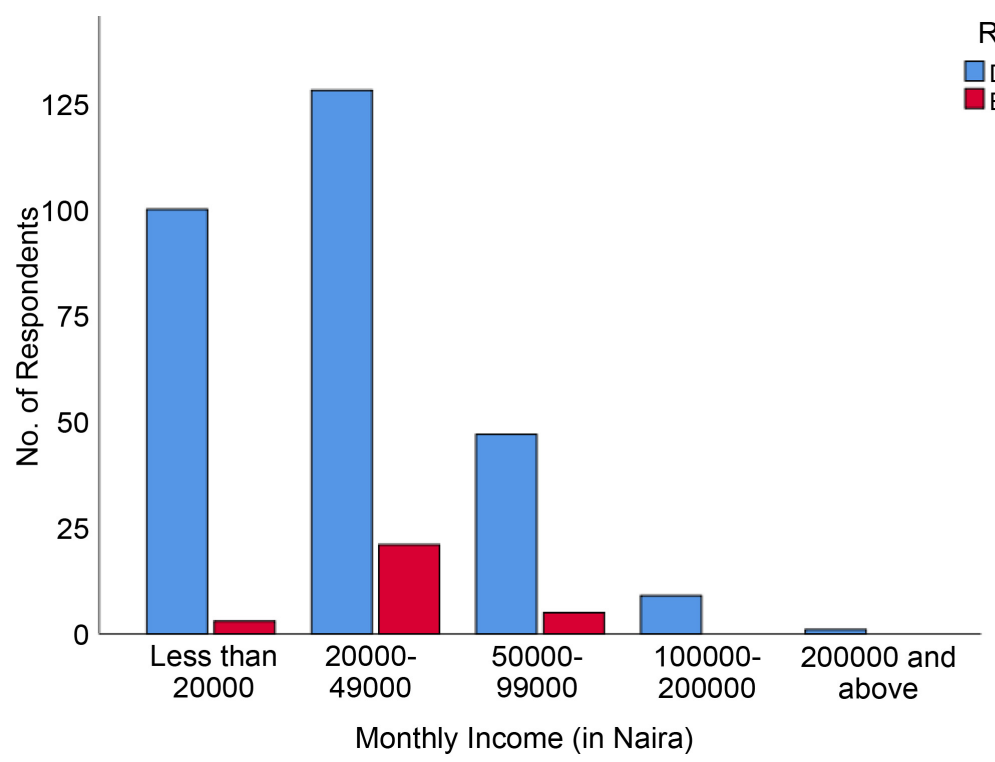

Respondents

Disempowered Empowered

Figure 2. Association between monthly income levels and empowerment.

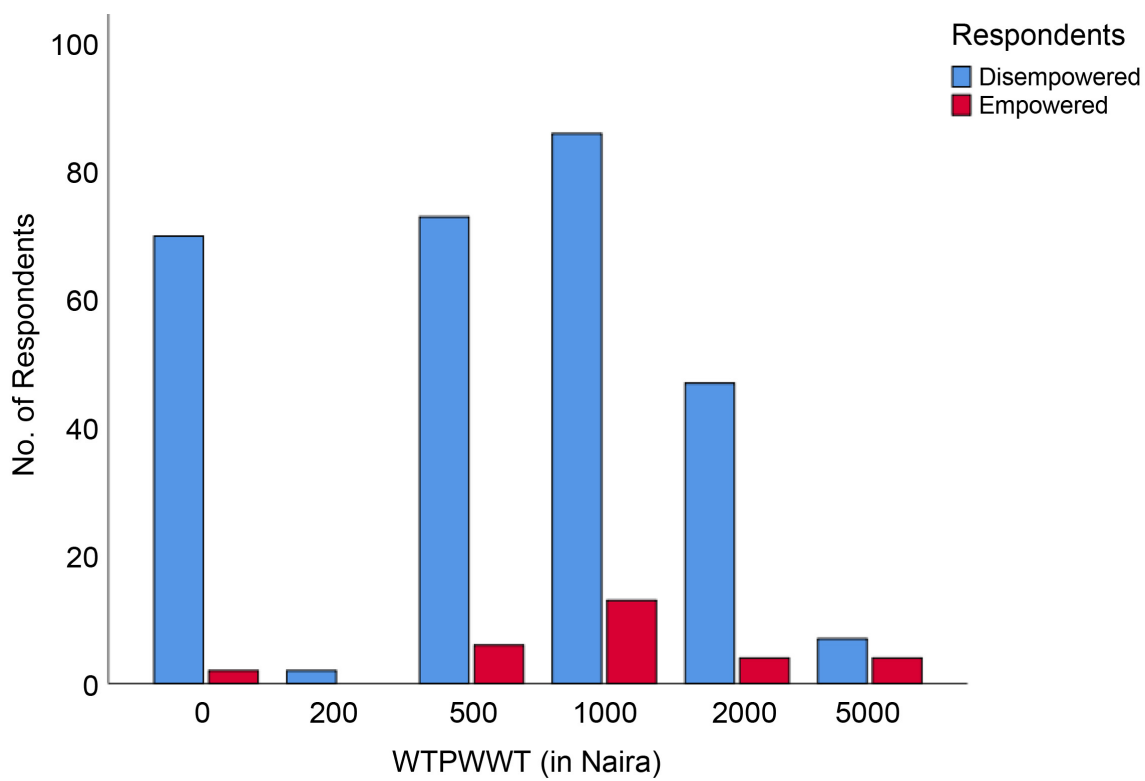

Figure 3. Association between empowerment and WTPWWT.

wealth ownership should be open to both men and women. Promoting gender equality must involve a discussion on wealth ownership equality. Research proves that women's assets inspire them; enhance well-being at the level of individuals, families, and communities; significantly improve their decision-making capabilities; [22] and have a greater effect on children's health and wellbeing [23]. Some studies indicate that it could also reduce the experience of women with domestic abuse [24] [25].

Other gender roles for women such as input into decisions about participation in WASH community activities, leadership in WASH accountability, input into WASH spending decisions, personal decisions on WASH roles and leadership in 
WASH implementation, largely led to inequalities in levels of women disempowerment. This indicates that women have been allowed little involvement in policy formulation and implementation of WASH projects despite the key role they play in delivering and protecting WASH for households [26]. Women play an integral role in household water management and safety, but have restricted access to water and are therefore more vulnerable to inadequate sanitation and hygiene management facilities than men [27].

\section{Conclusions}

In this paper, the novel EWI offers a way to track and measure the effects of gender and social inclusion in an initiative to evaluate the effectiveness of mainstreaming gender practices. More information is needed to critically understand the role of empowerment in relation to WASH. The incorporation of clean water and sanitation into financial integration programmes could be a sustainable approach to reach more women in order to achieve SDG 6.

Understanding how other social identities such as ethnicity, wealth index and cultural beliefs intersect with gender to influence empowerment in WASH is an important area for further research.

\section{Acknowledgements}

This work was supported by the Chinese Ministry of Commerce (MOFCOM) scholarship which is gratefully acknowledged. The authors would like to thank Prof. H. Wang for his critical review, comments and revision.

\section{Conflicts of Interest}

The authors declare no conflict of interest.

\section{Authors' Contribution}

Data curation: TO; DO.

Formal Analysis: TO; DO.

Investigation: TO; DO.

Resources: TO; AA.

Validation: DO.

Visualization: TO.

Writing-original draft: TO.

Writing-review \& editing: AA.

\section{References}

[1] Bisung, E. and Dickin, S. (2019) Concept Mapping: Engaging Stakeholders to Identify Factors That Contribute to Empowerment in the Water and Sanitation Sector in West Africa. SSM-Population Health, 9, Article ID: 100490. https://doi.org/10.1016/j.ssmph.2019.100490

[2] Kramer, H.K. (2018) Evaluating SDG Indicators 6.1.1 and 6.2.1 Taking into Consideration the Importance of Gender Equality. Master's Thesis, Water Resources 
Engineering and Management, Universität Stuttgart, Stuttgart.

[3] Kayser, G., Rao, N., Jose, R. and Raj, A. (2019) Water, Sanitation and Hygiene: Measuring Gender Equality and Empowerment. Bulletin of the World Health Organization, 97, 438-440. https://doi.org/10.2471/BLT.18.223305

[4] Stevenson, J., Ambelu, A., Caruso, B., Tesfaye, T. and Freeman, M. (2016) Community Water Improvement, Household Water Insecurity, and Women's Psychological Distress: An Intervention and Control Study in Ethiopia. PLOS ONE, 11, e0153432. https://doi.org/10.1371/journal.pone.0153432

[5] Bethan, C., Thomas, C., Craig, H., Kathryn, Y., Regine, H., Manaswini, R., et al. (2017) Understanding and Defining Sanitation Insecurity: Women's Gendered Experiences of Urination, Defecation and Menstruation in Rural Odisha, India. BMJ Global Health, 2, e000414. https://doi.org/10.1136/bmigh-2017-000414

[6] Bethany, C., Hannah, C., Regine, H., Kathryn, Y., Parimita, R., Belen, T., et al. (2018) The Association between Women's Sanitation Experiences and Mental Health: A Cross-Sectional Study in Rural, Odisha India. SSM-Population Health, 20, 257266. https://doi.org/10.1016/j.ssmph.2018.06.005

[7] Sommer, M., Ferron, S., Cavill, S. and House, S. (2015) Violence, Gender and WASH: Spurring Action on a Complex, Under-Documented and Sensitive Topic. Environment and Urbanization, 27, 105-116. https://doi.org/10.1177/0956247814564528

[8] S.E.I. (2020) Making Gender Count in Water, Sanitation and Health. 2019 Annual Report, Stockholm Environment Institute, Stockholm. https://www.sei.org/featured/making-gender-count-water-sanitation-health

[9] Caruso, B.A. and Sinharoy, S.S. (2019) Gender Data Gaps Represent Missed Opportunities in WASH. The Lancet Global Health, 7, e1617. https://doi.org/10.1016/S2214-109X(19)30449-8

[10] Jansz, S. and Wilbur, J. (2013) Women and WASH. Briefing Note. Water Supply \& Sanitation Collaborative Council and Water Aid, 2013.

[11] UNIFEM (2009) Progress of World's Women. Who Answers to Women? Gender and Accountability.

[12] Willetts, J., Halcrow, G., Carrard, N., Rowland, C. and Crawford, J. (2010) Addressing Two Critical MDGs Together: Gender in Water, Sanitation and Hygiene Initiatives. Pacific Economic Bulletin, 25, 162-176.

[13] Fisher, J., Cavill, S. and Reed, B. (2017) Mainstreaming Gender in the WASH Sector: Dilution or Distillation? Gender \& Development, 25, 185-204. https://doi.org/10.1080/13552074.2017.1331541

[14] Dickin, S., Bisung, E., Nansi, J. and Charles, K. (2020) Empowerment in Water, Sanitation and Hygiene Index. World Development, 137, Article ID: 105158. https://doi.org/10.1016/j.worlddev.2020.105158

[15] Alkire, S., Meinzen-Dick, R., Peterman, A., Quisumbing, A., Seymour, G. and Vaz, A. (2013) The Women's Empowerment in Agriculture Index. World Development, 52, 71-91. https://doi.org/10.1016/j.worlddev.2013.06.007

[16] Kabeer, N. (1999) Resources, Agency, Achievements: Reflections on the Measurement of Women's Empowerment. Development and Change, 30, 435-464.

https://doi.org/10.1111/1467-7660.00125

[17] Alsop, R. and Heinsohn, N. (2005) Measuring Empowerment in Practice: Structuring Analysis and Framing Indicators. Washington DC.

[18] Dery, F., Bisung, E., Dickin, S. and Dyer, M. (2020) Understanding Empowerment 
in Water, Sanitation, and Hygiene (WASH): A Scoping Review. Journal of Water, Sanitation and Hygiene for Development, 10, 5-15. https://doi.org/10.2166/washdev.2019.077

[19] Milligan, P., Njie, A. and Bennett, S. (2004) Comparison of Two Cluster Sampling Methods for Health Surveys in Developing Countries. International Journal of Epidemiology, 33, 469-476. https://doi.org/10.1093/ije/dyh096

[20] Malapit, H., Quisumbing, A., Meinzen-Dick, R., Seymour, G., Martinez, E., Heckert, J., et al. (2019) Development of the Project-Level Women's Empowerment in Agriculture Index (pro-WEAI). World Development, 122, 675-692.

https://doi.org/10.1016/j.worlddev.2019.06.018

[21] Gupta, S., Vemireddy, V., Singh, D. and Pingali, P. (2019) Adapting the Women's Empowerment in Agriculture Index to Specific Country Context: Insights and Critiques from Fieldwork in India. Global Food Security, 23, 245-255.

https://doi.org/10.1016/j.gfs.2019.09.002

[22] Agarwal, B. (1997) Bargaining' and Gender Relations: Within and beyond the Household. Feminist Economics, 3, 1-51. https://doi.org/10.1080/135457097338799

[23] W.D. Report (2012) Gender Equality and Development. World Bank, Washington DC.

[24] Panda, P. and Bina, A. (2005) Marital Violence, Human Development, and Women's Property Status in India. World Development, 33, 823-850.

https://doi.org/10.1016/j.worlddev.2005.01.009

[25] Manasi, B., Arjun, B. and Amrita, C. (2011) Marital Violence and Women's Employment and Property Status: Evidence from North Indian Villages. World Development, 39, 1676-1689. https://doi.org/10.1016/j.worlddev.2011.02.001

[26] Upadhyay, B. (2005) Women and Natural Resource Management: Illustrations from India and Nepal. Natural Resources Forum, 29, 224-232. https://doi.org/10.1111/j.1477-8947.2005.00132.x

[27] Wali, N., Georgeou, N., Simmons, O., Gautam, M.S. and Gurung, S. (2020) Women and WASH in Nepal: A Scoping Review of Existing Literature. Water International, 45, 222-245. https://doi.org/10.1080/02508060.2020.1754564 